\title{
BMJ Open Effectiveness of the Baby Friendly Community Initiative in Italy: a non-randomised controlled study
}

\author{
Adriano Cattaneo, ${ }^{1}$ Maria Enrica Bettinelli, ${ }^{2}$ Elise Chapin, ${ }^{3}$ Anna Macaluso, ${ }^{1}$ \\ Lílian Córdova do Espírito Santo, ${ }^{4}$ Anna Maria Murante, ${ }^{5}$ Marcella Montico, ${ }^{6}$ \\ on behalf of the BFCl Study Group
}

To cite: Cattaneo A, Bettinelli ME, Chapin $\mathrm{E}$, et al. Effectiveness of the Baby Friendly Community Initiative in Italy: a non-randomised controlled study. BMJ Open 2016;6:e010232.

doi:10.1136/bmjopen-2015010232

- Prepublication history and additional material is available. To view please visit the journal (http://dx.doi.org/ 10.1136/bmjopen-2015010232).

Received 9 October 2015 Revised 4 February 2016 Accepted 5 February 2016

CrossMark

For numbered affiliations see end of article.

Correspondence to Adriano Cattaneo; adriano. cattaneo@burlo.trieste.it

\section{ABSTRACT}

Objective: To assess the effectiveness of the Baby Friendly Community Initiative (BFCl) on exclusive breast feeding at 6 months.

Design: Controlled, non-randomised trial.

Setting: 18 Local Health Authorities in 9 regions of Italy.

Participants: 5094 mother/infant dyads in 3 cohorts were followed up to 12 months after birth in 3 rounds of data collection: at baseline, after implementation of the intervention in the early intervention group and after implementation in the late intervention group. 689 $(14 \%)$ dyads did not complete the study.

Intervention: Implementation of the 7 steps of the $\mathrm{BFCl}$.

Main outcome measures: The rate of exclusive breast feeding at 6 months was the primary outcome; breast feeding at discharge, 3 and 12 months was also measured.

Results: The crude rates of exclusive breast feeding at discharge, 3 and 6 months, and of any breast feeding at 6 and 12 months increased at each round of data collection after baseline in the early and late intervention groups. At the end of the project, $10 \%$ of infants were exclusively breast fed at 6 months and $38 \%$ were continuing to breast feed at 12 months. However, the comparison by adjusted rates and logistic regression failed to show statistically significant differences between groups and rounds of data collection in the intention-to-treat analysis, as well as when compliance with the intervention and training coverage was taken into account.

Conclusions: The study failed to demonstrate an effect of the $\mathrm{BFCl}$ on the rates of breast feeding. This may be due, among other factors, to the time needed to observe an effect on breast feeding following this complex intervention.

\section{INTRODUCTION}

The Baby Friendly Hospital Initiative (BFHI) is an evidence-based effective intervention that contributes to increasing the initiation, exclusivity and duration of breast feeding. ${ }^{12}$

\section{Strengths and limitations of this study}

- Implementation of a complex multisectoral intervention for the protection, promotion and support of breast feeding, with synergistic engagement of many different actors.

- Controlled, though non-randomised, trial with possible effect measured in three rounds of data collection, at baseline and before and after a phased implementation of the intervention.

- Rates of breast feeding compared between groups of local health authorities by intention to treat, compliance with the intervention and training coverage.

- Rates of breast feeding increased overall during the 4 years of the study, but this may not have had the power to identify small differences as significant.

- The effects of a complex intervention such as the Baby Friendly Community Initiative may need more than the 4 years of the study to be observed.

Alone, however, it cannot achieve the goals recommended by the WHO, UNICEF and many national and professional policies, that is, exclusive breast feeding (EBF) for 6 months and continued breast feeding, with adequate complementary foods, up to 2 years and beyond. ${ }^{3-6}$ Worldwide, rates of EBF to 6 months fall short of those recommended: $;^{7-9}$ interventions at the community level, in addition to the hospital-based ones, are needed to improve them. ${ }^{10}$ Several community interventions, such as primary care-based educational programmes, ${ }^{11}{ }^{12}$ competent professional support at home or in health facilities, ${ }^{13}$ home visits by trained professionals, ${ }^{14}$ homebased peer counselling, ${ }^{15}$ or the involvement of fathers, ${ }^{16}{ }^{17}$ have been shown to be effective. In some countries, these interventions have been integrated into Baby Friendly Community Initiatives (BFCIs), ${ }^{18-20}$ generally considered as an appropriate framework. ${ }^{21}$ 
The Italian Committee for UNICEF, which promotes and coordinates the BFHI in Italy, established a working group to adapt and develop the BFCI for the national health system, in collaboration with the Local Health Authority (LHA) of Milan, where it was initially piloted and later launched in 2007. The BFCI is based on the seven-point plan used in the UK and New Zealand, and includes tools for planning, implementation, monitoring and evaluation described in a companion paper. $^{22}$ Briefly, the seven steps of the BFCI (box 1) are supposed to be implemented in all the non-hospital-based health facilities of an LHA. These include health centres, mother and child health clinics, family health centres, public and private medical, obstetric and paediatric practices, day care centres, and, where present, public pharmacies. All the health and social workers of these facilities have to be trained, in courses of different duration, to implement a policy previously developed by a multidisciplinary team and approved by the LHA management. Health professionals are trained to help breast feeding as well as formula-feeding mothers when and where they ask for support. Moreover, by implementing step 6, the LHA is required to create breastfeedingfriendly environments in its premises and facilities, as well as in other community and public places. So-called 'baby pit stops' are created in public locations or businesses (shops, libraries, pharmacies, etc) where nursing mothers can feel welcome. These places are free, do not require any purchase and become part of a network promoted by UNICEF Italy, with a periodic review by a consumers' group or volunteers. Other initiatives included in this step are breastfeeding-friendly day care and workplaces which are designed so that breast feeding can once again be considered an act that can be done in public. The day care centres have guidelines for the use of mother's milk and welcome breastfeeding mothers who want to feed their children when they drop them off or pick them up. Step 7 focuses on networking with other services and mother-to-mother and peer support groups that are not part of the health system. In addition to these groups, support may be offered through a

Box 1 The seven steps of the Baby Friendly Community Initiative

1. Have a written breastfeeding policy that is routinely communicated to all staff.

2. Train all staff to implement the breastfeeding policy.

3. Inform all pregnant women and their families about the benefits and management of breast feeding.

4. Support mothers to initiate and sustain breast feeding.

5. Encourage exclusive breast feeding up to 6 months of age, the introduction of appropriate complementary foods after 6 months, and continued breast feeding.

6. Provide a welcoming atmosphere for breastfeeding families.

7. Promote cooperation between healthcare staff, breastfeeding support groups and the local community. breastfeeding helpline, local health clinics, hospitals or baby-friendly physicians' offices, or breastfeedingfriendly pharmacies (BFF). The $\mathrm{BFF}$ is a separate programme that requires all staff to complete a $15 \mathrm{~h}$ course to promote breast feeding as the norm, to keep breast milk substitutes, bottles and teats behind the counter with prescription drugs, to sell them only on specific request and to abide, like all health facilities and professionals in the LHA, by the International Code of Marketing of Breast-Milk Substitutes.

In 2009, 18 LHAs, which had expressed an interest in the BFCI, accepted the invitation from the Italian Committee for UNICEF of working towards BFCI accreditation. This was an opportunity to set up a research project to look at the effectiveness of the BFCI in terms of rates and duration of EBF at 6 months, a recognised research priority. ${ }^{23}$ The methods and some baseline data of this project have already been reported in a second companion paper. ${ }^{24}$ This third paper reports the final results.

\section{METHODS}

The methods of this research project have already been described. $^{24}$ Briefly, this controlled trial involved 18 LHAs in nine regions of northern and central Italy. Some of these LHAs, however, had already started implementing BFCI activities before the study was designed: Milan, because it had a leading role in developing the materials and tools and pilot testing them; others, because they had been part of the working group that adapted the BFCI for Italy, or had previously worked on developing draft policies, or had conducted some limited staff training, especially where there was a Baby Friendly Hospital (BFH). For these reasons, it was impossible to randomise the 18 LHAs into intervention and control groups. It was instead decided to implement the seven steps in a phased way, first in an early intervention group of LHAs that had already implemented some BFCI activities (LHAs 5, 6, 8, 9, 10, 14, 15, 16, 18), and then, after about 12 months, in the remaining ones (LHAs 1, 2, 3, 4, 7, 11, 12, 13, 17). Assignment to the early or late intervention group was preceded by pairing LHAs on the basis of reported rates of EBF at around 5 months of age, size of the population, and setting and population density (ie, whether the LHA was mostly urban or rural). Figure 1 shows the study design and the sample size at each round of data collection, at baseline, after implementation of activities in the early intervention group, and after implementation in the late intervention group.

The rate of EBF at 6 months was the primary outcome of the study. To compare these rates between groups and within them over time, data were gathered in three rounds. At each round of data collection, starting in the fall of 2009, cohorts of infants were followed from birth to 12 months, with interviews at discharge and at 3,6 and 12 months, in each of the three rounds. Mothers 


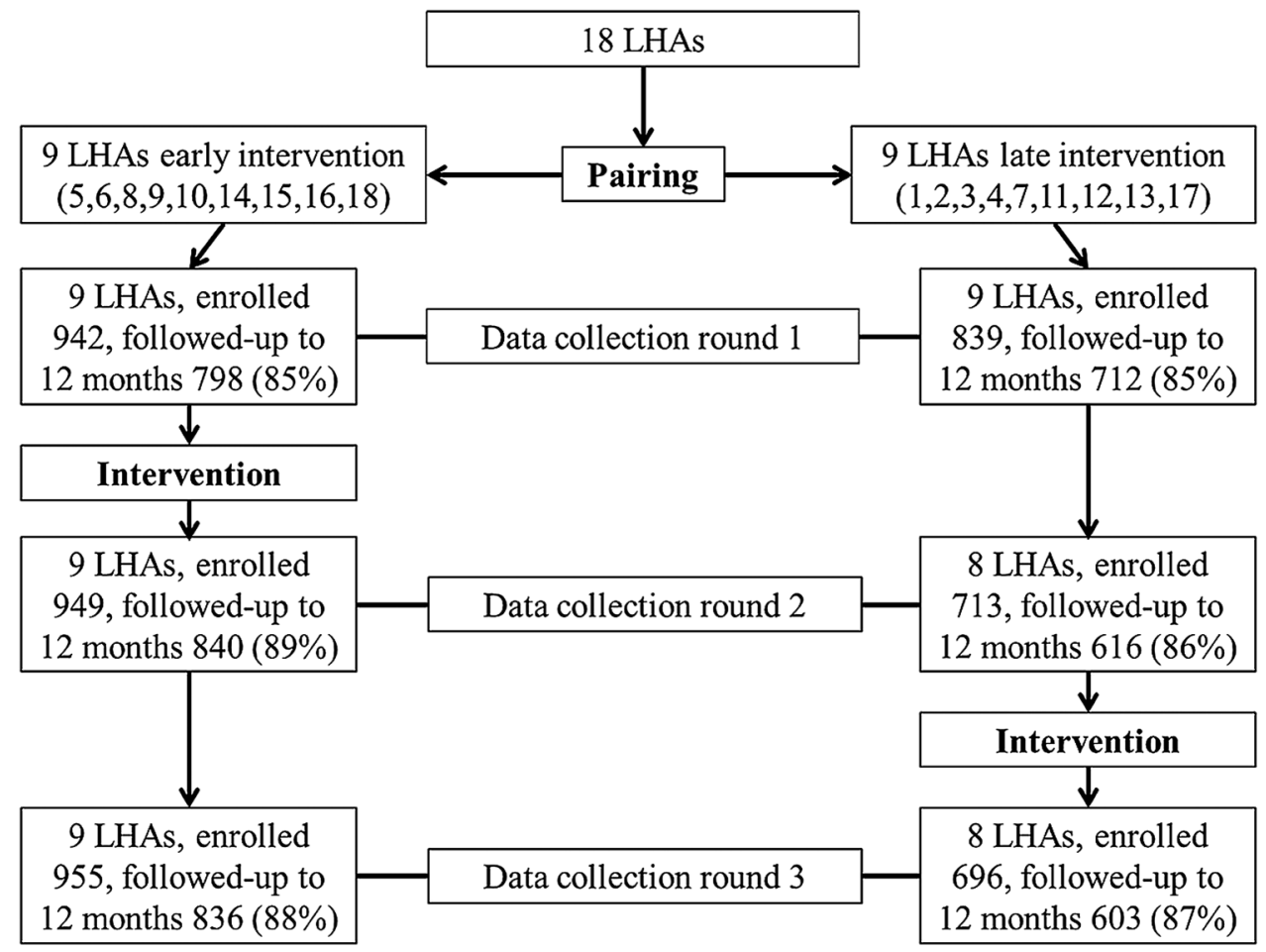

Figure 1 A sketch of the study design. LHA, Local Health Authority.

were recruited consecutively in the hospitals serving the 18 LHAs, until the intended sample size was attained. After obtaining informed consent, the first interview with the mother was conducted face to face just before discharge using a 36-item questionnaire that included three questions on feeding both within the previous $24 \mathrm{~h}$ and from birth (Has the baby had breast milk? Has the baby had formula? Has the baby had other fluids and, if so, what?), questions on potential confounders, as well as basic information used to identify the participant. If, for any reason, it was impossible to interview the mother during hospital stay, the interview was carried out by telephone within 1 week of giving birth; this occurred with $212(12 \%)$ mothers. These interviews were performed by the staff in charge of the BFCI in each LHA. The interviews at 3, 6 and 12 months included five yes/no questions on foods and fluids taken in the previous $24 \mathrm{~h}$ (breast milk, formula, animal milks, non-nutritive fluids, and solids or semisolids), plus an additional question for infants fed only breast milk on other foods and fluids taken in the previous 7 days, to compensate for the well-known overestimate of EBF using a $24 \mathrm{~h}$ recall. ${ }^{25} 26$ These questions, complemented in the interview at 12 months by questions on breastfeeding problems and ways they were solved or not, were administered by researchers of the Management and Health Laboratory at Scuola Superiore Sant'Anna, Pisa, specialised in conducting surveys using computerassisted telephone interviewing (CATI) methods. These interviewers were unaware of the assignment to the early or late intervention groups. The different categories of feeding were automatically derived from the different combinations of answers. ${ }^{27}{ }^{28}$ All infants were followed up to 12 months of age irrespective of their feeding status. The interviews at 12 months in the third round of data collection were concluded in March of 2012.

The sample size for each cohort was established on the assumption that the BFCI could result in a $10 \%$ increase in the rate of EBF at 6 months, from the baseline $25 \%$ estimate, as a weighted and adjusted average of the range from $10 \%$ to $60 \%$ reported for 2007 or 2008 by the 18 LHAs at around 5 months of age. These reports were based on data gathered most often at immunisation or, less often, during small cross-sectional or longitudinal surveys, with questionnaires, definitions of feeding categories and recall periods that were not standardised, and on samples that might have not represented the population. On the basis of the above assumption, the sample size for a controlled trial with a precision of $5 \%$ and a power of $80 \%$ would amount to 348 participants per study arm. Owing to the cluster design of the study, this number was doubled to 1392 participants, 696 per study arm, considering a possible and conservative design effect of 2 . The final sample size of 1740 mother-infant pairs per round of data collection takes into account a possible $20 \%$ loss to follow-up. This sample size was then distributed among the 18 LHAs in proportion to their estimated number of annual births. Exclusion criteria were a birth weight lower than $2000 \mathrm{~g}$, any postpartum condition that required admission into a neonatal intensive care unit, the practical impossibility of conducting the interview (mother or relative unable to understand Italian, English, French or Spanish), and residence outside the 
area covered by the LHA. Twins were recruited as separate participants. As described in the first companion paper, ${ }^{22}$ data collection included a self-assessment questionnaire completed by the 18 LHAs on the progress made in implementing the seven steps, each step having a set of 3-11 criteria based on the same model used for the self-assessment of the BFHI. ${ }^{29}$ In addition, each LHA was supposed to develop annual action plans and to report on the degree of implementation.

After a phase of planning and pilot testing of the tools, ${ }^{22}$ baseline data collection started in September 2009 and was successfully completed; the second and third rounds were completed as planned. Data from face-to-face interviews were manually inputted into customised EpiData Files, and later exported to MS Excel, by the research assistants in each of the 18 sites. Those from the CATI system (at 3,6 and 12 months) were recorded answer-by-answer in real time and automatically saved into a separate relational database, one for each round of data collection, and then extracted to MS Excel files. Finally, all the data from each round were integrated into a single MS Excel file in Trieste, using the individual ID codes for record linkage. Data were then checked for completeness, consistency and accuracy, and research assistants at the 18 sites were notified of possible mistakes for correction after comparison with the original paper records. Data analysis was carried out using Stata V.13. Differences in baseline characteristics were analysed with $\chi^{2}$ test or $\mathrm{t}$ test as appropriate. Differences in rates of breast feeding between early and late intervention groups at different time points were assessed with logistic regression models using a backward stepwise selection approach that retained only the variables associated with breast feeding at the 0.05 level of significance and took into account the effect of the cluster design (cluster command in Stata V.13). The tested variables were: maternal age, nationality, education, paid occupation, living with a partner, smoking before and during pregnancy, maternal pre-pregnancy body mass index, gestational diabetes, parity, twin pregnancy, attending an antenatal course, birth in a BFH, type of delivery, analgesia or anaesthesia in labour, intention to breast feed, gestational age, birth weight, timing of the first breast feed, rooming-in, baby-led feeding, use of bottle and/or pacifier during hospital stay. The results of the logistic regression models were used to obtain adjusted breastfeeding rates at different ages, with $95 \%$ CIs adjusted for the effect of the cluster design.

\section{RESULTS}

Online supplementary appendix table A1 shows the number of participants enrolled and followed up to 12 months by LHA in the early and late intervention groups and by round of data collection. The final database includes 5094 records of enrolled mother-baby dyads, including 107 twins (2\%), 126 dyads less than the intended overall sample size due to the failure of two LHAs, both in the late intervention group, to participate in one of the data collection rounds. For the analysis at 3 months, 4704 dyads are available, a loss of $7.7 \%$; at 6 months, data are available on 4572 dyads, a further $2.8 \%$ loss; at 12 months, 4405 dyads completed the series of interviews, contributing to a total loss to follow-up of $13.5 \%$ (range of 9-20\% among LHAs, no significant differences by intervention group and by round of data collection), much less than the $20 \%$ predicted when the sample size was calculated. A total of 281 eligible mothers declined to be enrolled for various reasons; there were no significant differences between participant and non-participant mothers except for nationality, the proportion of foreign women being higher among the latter. Table 1 shows the characteristics of the mothers and infants included in the analysis, by study group. The demographic characteristics of the sample were similar to national averages in terms of age and education, while the percentage of women with a paid employment was slightly higher. ${ }^{30}$ More women in the sample attended antenatal classes than do those on average throughout the country $(44 \%$ vs $35 \%) .{ }^{31}$ It is also worth noting that the rate of caesarean delivery $(27-29 \%)$ was well below the national average of $38 \%$, although slightly fewer women had term births (90-92\% vs $93 \%$ ). There were several statistically significant differences between early and late intervention groups; these differences were accounted for in the multivariate analysis. The significantly better perinatal care practices reported by mothers in the early intervention group are probably due to the higher percentage of births in BFHs.

Figures 2-6 show the crude rates of EBF at discharge (recall from birth) and at 3 and 6 months (recall 7 days), as well as the crude rates of any breast feeding $(\mathrm{ABF})$ at 6 and 12 months (recall $24 \mathrm{~h}$ ). By the end of the project, almost $70 \%$ of infants were exclusively breast fed at discharge, with an increasing trend between rounds 1 and 3 of data collection, and with great variation among sites (range 26-93\%). Both the upward trend between the first and the third rounds of data collection, and the variation among sites, are present at 3 , 6 and 12 months for EBF and ABF. At the third round of data collection, the rates of EBF were fairly high at 3 months (54\% at round 3, range 36-66\%), but dropped to $8 \%$ (range $1-23 \%$ ) at 6 months. These rates were lower than expected, even when considering the figures for the $24 \mathrm{~h}$ recall: $10 \%$ (range 3-23\%). At the end of the project, almost $38 \%$ of infants were continuing to breast feed at 12 months.

Crude rates, however, cannot be used for comparisons, as this was not a randomised trial and confounding has to be considered. Table 2 shows the adjusted rates of $\mathrm{EBF}$ and $\mathrm{ABF}$ at different ages and with different recall periods by intervention group and round of data collection. Though there was a clear pattern of higher rates in the early intervention group, there were no statistically 
Table 1 Characteristics of the mothers and infants included in the analysis, by study group

\begin{tabular}{|c|c|c|c|}
\hline & Early intervention & Late intervention & p Value \\
\hline Mean (SD) age (years) & $32(5)$ & $32(5)$ & 0.121 \\
\hline Mean (SD) education (years) & $14(4)$ & $13(4)$ & $<0.001$ \\
\hline Employment: paid occupation & $76 \%$ & $78 \%$ & 0.095 \\
\hline Italian & $85 \%$ & $85 \%$ & 0.535 \\
\hline Living with the partner & $97 \%$ & $96 \%$ & 0.004 \\
\hline \multicolumn{4}{|l|}{ Smoking } \\
\hline Before pregnancy & $29 \%$ & $27 \%$ & 0.109 \\
\hline During pregnancy & $11 \%$ & $8 \%$ & 0.003 \\
\hline \multicolumn{4}{|l|}{ Referred BMI } \\
\hline$<25$ & $80 \%$ & $79 \%$ & 0.436 \\
\hline 25 to 29.9 & $14 \%$ & $15 \%$ & \\
\hline$\geq 30$ & $6 \%$ & $6 \%$ & \\
\hline Gestational diabetes & $7 \%$ & $8 \%$ & 0.021 \\
\hline Primiparae & $57 \%$ & $54 \%$ & 0.053 \\
\hline Attendance at antenatal classes & $44 \%$ & $44 \%$ & 0.716 \\
\hline At least one session on BF & $82 \%$ & $87 \%$ & 0.002 \\
\hline Delivery at term (38-41 weeks) & $92 \%$ & $90 \%$ & 0.003 \\
\hline C-section rate & $27 \%$ & $29 \%$ & 0.058 \\
\hline Anaesthesia or analgesia during labour/delivery (including C-section) & $55 \%$ & $60 \%$ & $<0.001$ \\
\hline Mean (SD) birth weight $(g)$ & $3304(443)$ & $3283(443)$ & 0.092 \\
\hline Previous BF experience & $41 \%$ & $44 \%$ & 0.126 \\
\hline \multicolumn{4}{|l|}{ Of which } \\
\hline$<6$ months & $31 \%$ & $37 \%$ & 0.034 \\
\hline 6 to 12 months & $45 \%$ & $42 \%$ & \\
\hline 13 to 24 months & $20 \%$ & $18 \%$ & \\
\hline$>24$ months & $4 \%$ & $3 \%$ & \\
\hline Intention to breastfeed current baby & $99 \%$ & $98 \%$ & 0.126 \\
\hline Exclusively for at least 6 months & $82 \%$ & $80 \%$ & 0.184 \\
\hline Birth in a Baby Friendly Hospital & $32 \%$ & $27 \%$ & $<0.001$ \\
\hline Baby latched on within $1 \mathrm{~h}$ & $61 \%$ & $67 \%$ & $<0.001$ \\
\hline Rooming-in (24 h/day, all infants) & $77 \%$ & $80 \%$ & 0.080 \\
\hline Baby-led BF (breastfed infants) & $90 \%$ & $89 \%$ & 0.246 \\
\hline Baby used bottle (all infants) & $20 \%$ & $18 \%$ & 0.001 \\
\hline Baby used pacifier (all infants) & $19 \%$ & $26 \%$ & $<0.001$ \\
\hline
\end{tabular}

significant differences between groups and rounds of data collection as far as adjusted rates at discharge (not shown) are concerned. The lack of a statistically significant difference between groups had already been noted at baseline,${ }^{24}$ when it was in fact expected because sites were paired by breastfeeding rates, and persisted through the second and third rounds of data collection. Table 2 shows an upward trend of the adjusted rates of breast feeding between rounds of data collection, with the exception of EBF and ABF at 6 months in the early intervention group. Yet none of the differences between and within groups is statistically significant. The removal of twins from the data set did not change the results.

Since the periodic self-assessments had revealed that some of the study sites were making progress in the implementation of the seven steps, while others were lagging behind, we carried out a comparison by compliance with the intervention, in addition to the analysis by intention to treat. Table 3 shows the same adjusted rates of breast feeding of table 2 after regrouping the 18
LHAs by compliance with the intervention. This comparison shows some statistically significant differences between groups (EBF at 3 months in rounds 1 and 3 , and $\mathrm{ABF}$ at 6 months in rounds 2 and 3) and between rounds (EBF at 3 months between rounds 1 and 3 in the non-compliance group), but it does not show an effect of the intervention. We repeated the same statistical analysis using staff training to regroup the 18 LHAs into groups with higher and lower training coverage; results (not shown but available on request) and interpretation did not change. It is interesting to note, however, that, despite the apparent lack of effect of the intervention and despite similar adjusted rates of initiation (between $65 \%$ and $72 \%$ in both groups), the LHAs in the compliance and higher training coverage groups presented consistently higher rates of breast feeding throughout the first year of life. Once again, the removal of twins did not change the results.

We also carried out a logistic regression analysis including all the variables used to adjust the rates of 
a Round 1 Round $2 \square$ Round 3

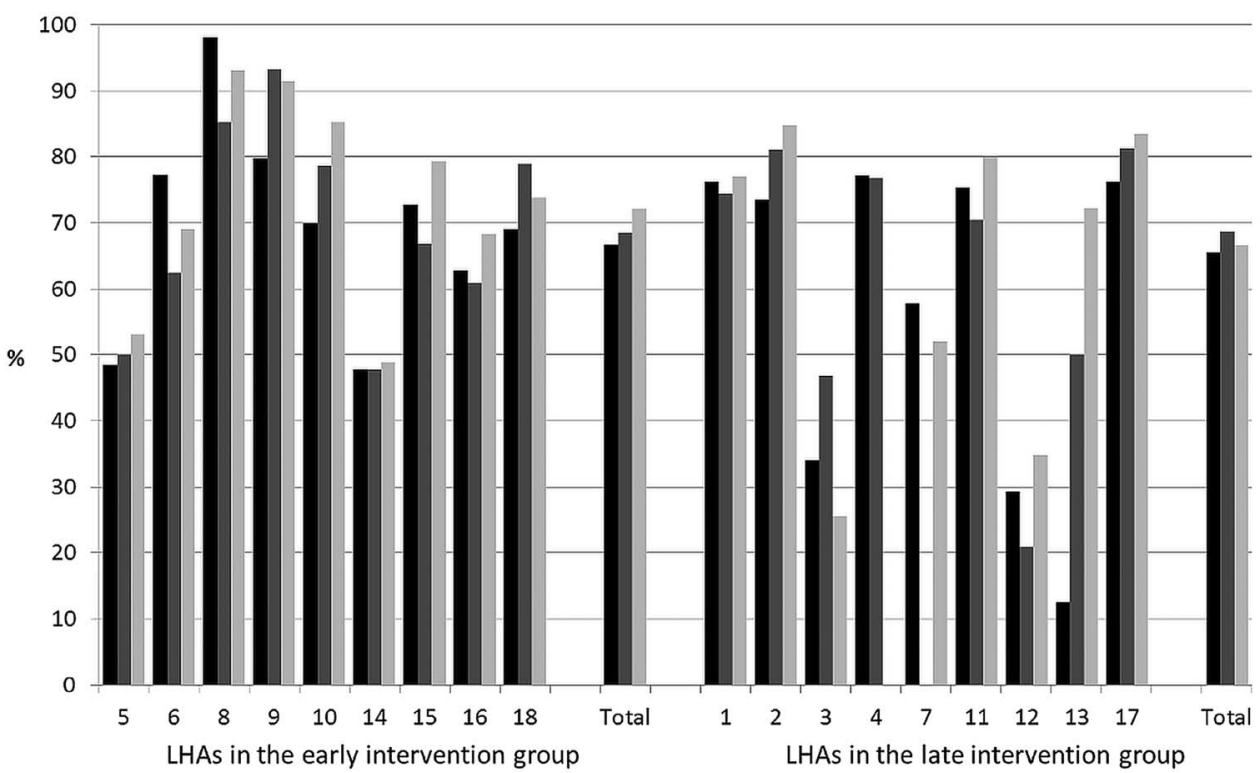

Figure 2 Rates of exclusive breast feeding at discharge (recall from birth) by site, group and round of data collection. LHA, Local Health Authority.

breast feeding, plus the rates of EBF at discharge (recall from birth). Online supplementary appendix tables A2 and A3 show the adjusted rates of breast feeding and the ORs, with their respective $95 \%$ CIs, by early and late intervention and by compliance and non-compliance, respectively, and by round of data collection, using the rates of the late intervention and non-compliance groups at round 1 as comparators. Using this logistic regression model, a small number of ORs result in statistically significant differences. These differences, however, do not indicate a clear association between the BFCI intervention, or compliance with it, and increased rates of breast feeding.
Finally, we analysed the answers mothers gave at the 12-month interview when asked if they had had problems with breast feeding, where they had looked for help, and whether they thought that those providing help had solved their problems or not. Overall, the 5094 mothers reported 1082 problems, mainly those relating to the breast and nipple (39\%), not enough milk (32\%) and difficulties latching the baby on $(20 \%)$, with no statistically significant differences between groups and rounds of data collection. There were no differences also in the percentage of mothers who sought help for these problems either. Some relevant statistically significant differences $(p<0.05)$ were found when mothers
Figure 3 Rates of exclusive breast feeding at 3 months (recall 7 days) by site, group and round of data collection. LHA, Local Health Authority.

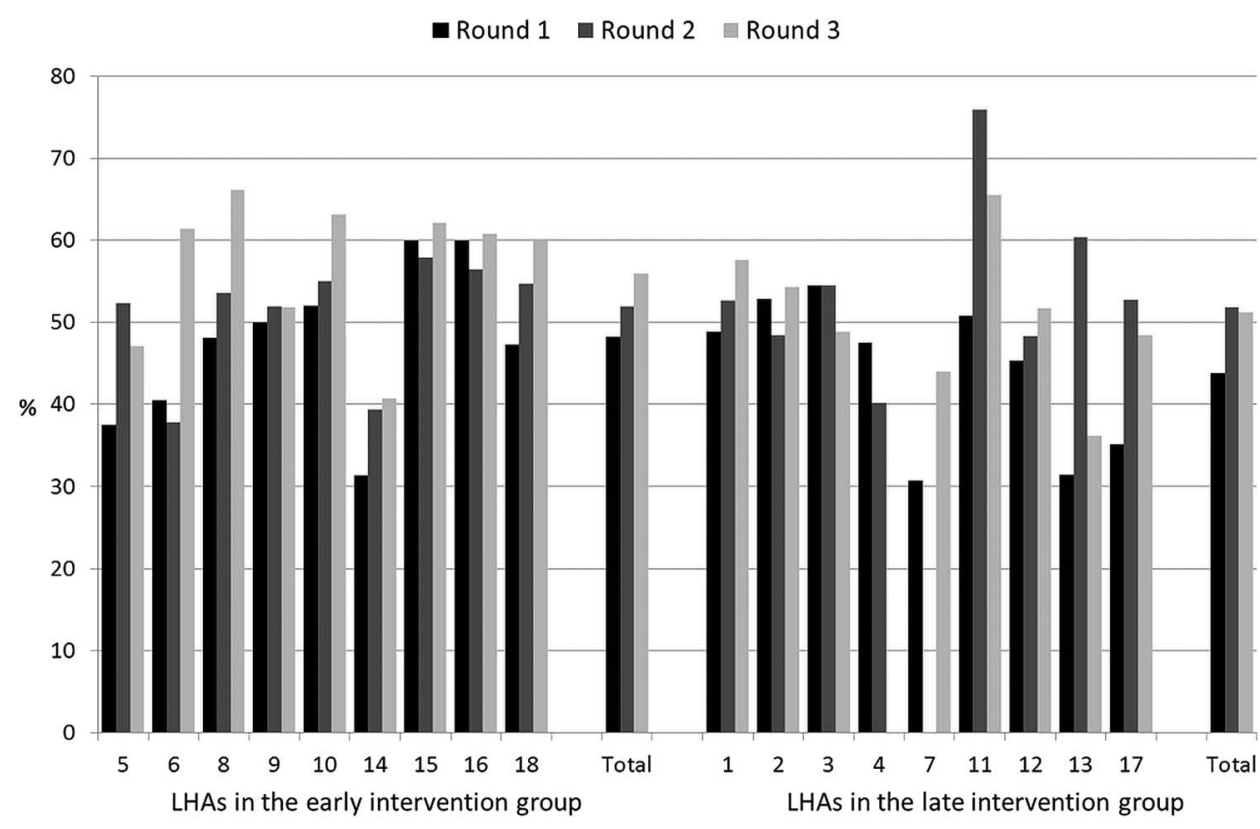


-Round 1 Round 2 Round 3

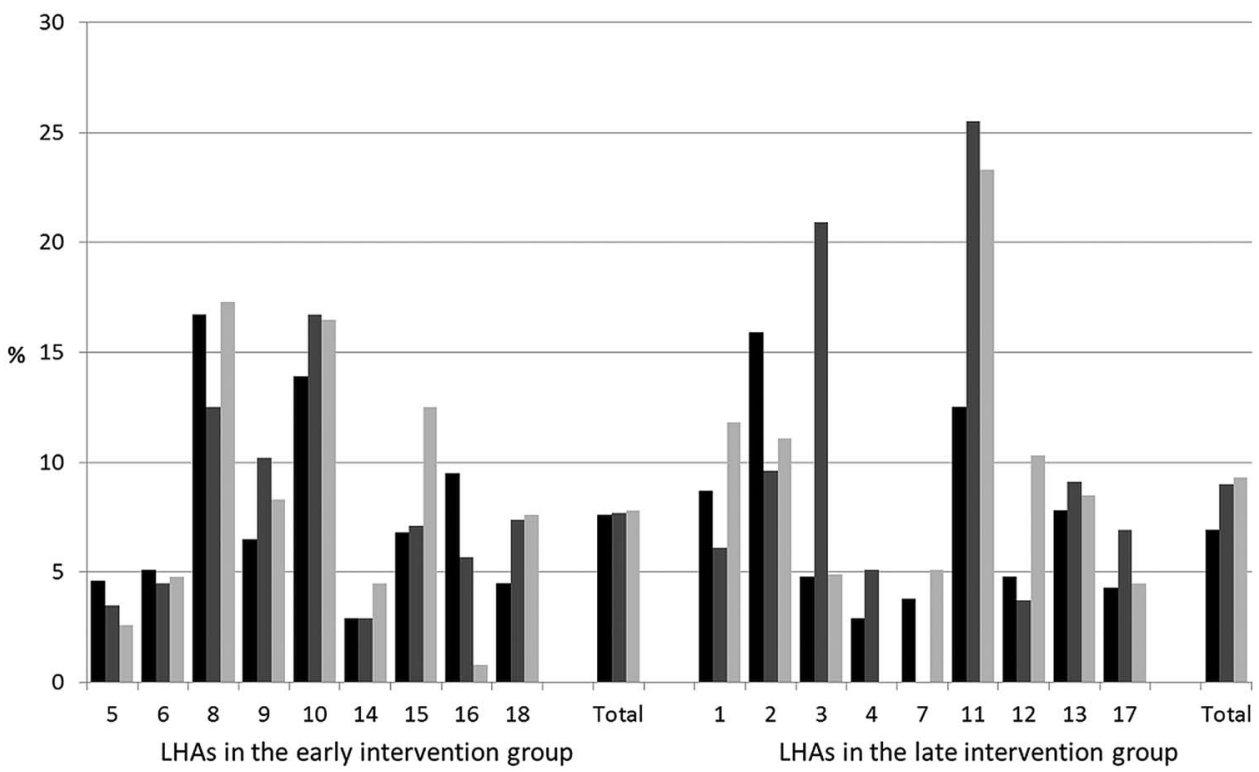

Figure 4 Rates of exclusive breast feeding at 6 months (recall 7 days) by site, group and round of data collection. LHA, Local Health Authority.

were asked to evaluate on a Likert scale the help received by level of usefulness in solving their problems. Mothers in the early intervention group classified this help as useful or very useful in $72 \%, 78 \%$ and $82 \%$ of cases in rounds 1,2 and 3, respectively, compared with $63 \%, 72 \%$ and $73 \%$ of mothers in the late intervention group.

\section{DISCUSSION}

The protection, promotion and support of breast feeding in a community is a complex, challenging and multisectoral set of interventions that need synergistic engagement by a number of different actors. ${ }^{32}$ Our nonrandomised controlled study measured the effect of the BFCI on the breastfeeding rates of a community, not just among infants served by health services. It failed to demonstrate a statistically significant effect, in particular on the rates of EBF at 6 months, the primary outcome under scrutiny. Failure to demonstrate an effect does not necessarily mean that there was no effect. As shown by our figures and tables, the rates of breast feeding went up during the project, which lasted $\sim 4$ years. These increases, however, occurred in the LHAs of both groups, whether they were early or late implementers of
Figure 5 Rates of any breast feeding at 6 months (recall $24 \mathrm{~h}$ ) by site, group and round of data collection. LHA, Local Health Authority.

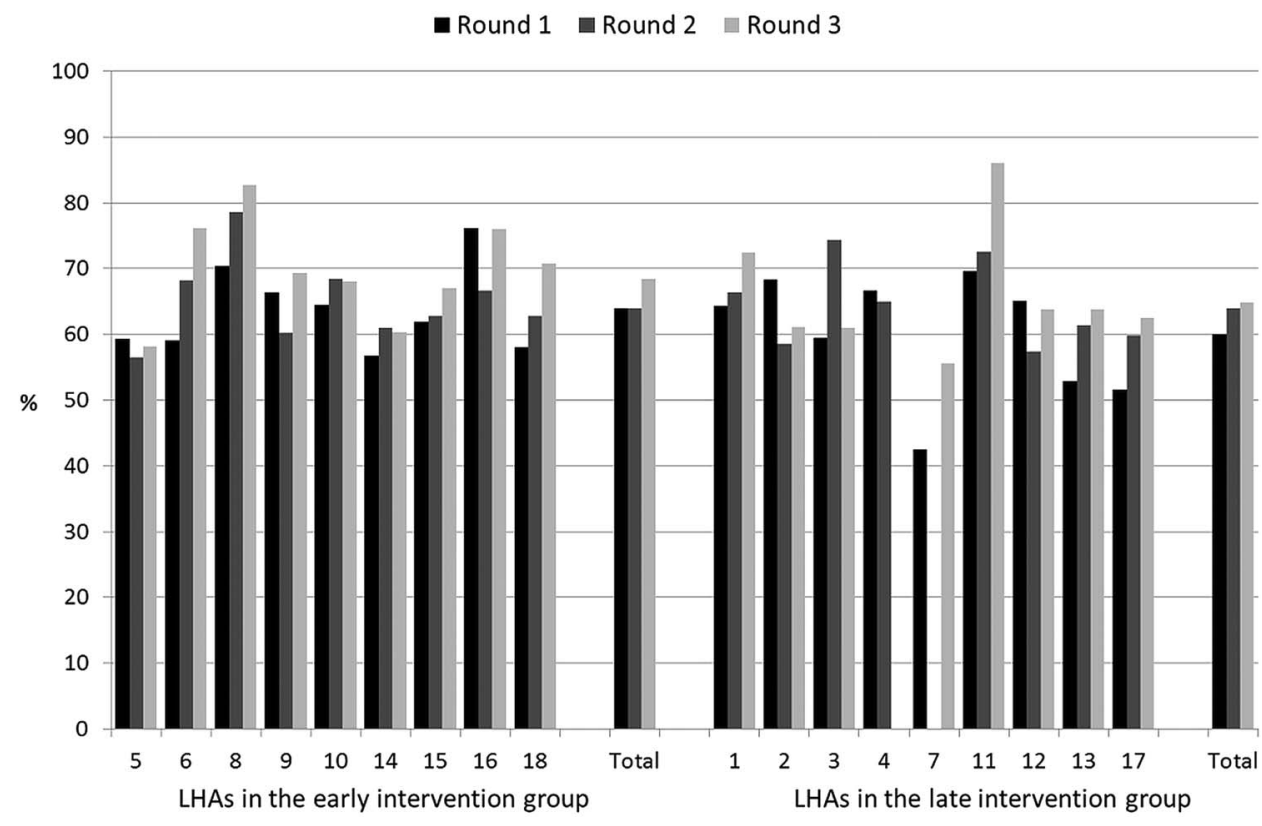




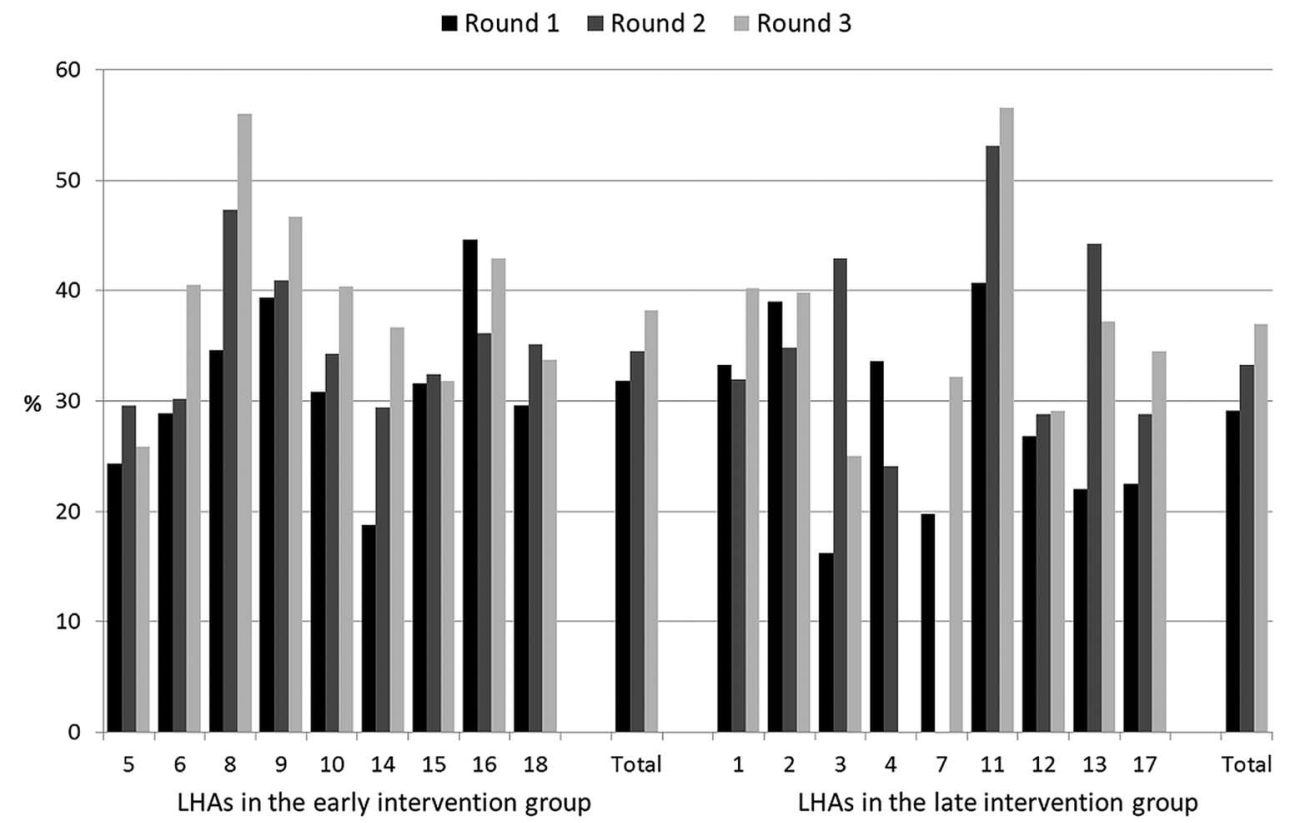

Figure 6 Rates of any breast feeding at 12 months (recall $24 \mathrm{~h}$ ) by site, group and round of data collection. LHA, Local Health Authority.

the seven steps, whether they complied with them to a greater or lesser extent, and whether they achieved a higher or lower training coverage. None of the differences were statistically significant. There are many possible explanations for this.

First, the study may not have had the power to identify small differences as significant. The sample size, in fact, was established on the assumption that the baseline rate of EBF at 6 months would be around $25 \%$ and that we would be able to detect an increase of $10 \%$. To our surprise, the baseline rate of $\mathrm{EBF}$ at 6 months was around $10 \%,{ }^{24}$ and it went up by only $1-2 \%$ in 4 years. The initially presumed $25 \%$ rate was probably the result of inaccurate local statistics. Also, there was a large drop in EBF between 3 and 6 months, most likely due to recommendations by the majority of paediatricians to introduce solids between 4 and 6 months, given the lack of significant differences by maternal occupation and return to work. Second, the lag time between the implementation of the seven steps and their effects on the

Table 2 Adjusted rates (per cent) of exclusive (EBF) and any (ABF) breast feeding at different ages and with different recall periods by intervention group and round of data collection

\begin{tabular}{|c|c|c|c|c|c|c|c|}
\hline \multirow[b]{2}{*}{ Breastfeeding indicators } & \multirow[b]{2}{*}{ Round } & \multicolumn{3}{|c|}{ Early intervention group } & \multicolumn{3}{|c|}{ Late intervention group } \\
\hline & & $\mathbf{n}$ & Per cent & $(95 \% \mathrm{Cl})$ & $\mathrm{n}$ & Per cent & $(95 \% \mathrm{Cl})$ \\
\hline \multirow[t]{3}{*}{ EBF at 3 months (recall $24 \mathrm{~h}$ ) } & 1 & 852 & 58.1 & (52.1 to 64.1$)$ & 746 & 52.8 & (47.3 to 58.4 ) \\
\hline & 2 & 845 & 57.5 & (54.4 to 60.7 ) & 645 & 53.6 & (45.7 to 61.6$)$ \\
\hline & 3 & 867 & 62.3 & (59.8 to 64.7$)$ & 633 & 57.9 & (53.8 to 62.1 ) \\
\hline \multirow[t]{3}{*}{ EBF at 3 months (recall 7 days) } & 1 & 852 & 49.6 & (43.5 to 55.7 ) & 746 & 43.4 & (38.3 to 48.5$)$ \\
\hline & 2 & 845 & 52.9 & (48.7 to 57.2 ) & 645 & 50.0 & (41.5 to 58.4$)$ \\
\hline & 3 & 867 & 55.9 & (52.3 to 59.4$)$ & 633 & 51.1 & (47.5 to 54.6$)$ \\
\hline \multirow[t]{3}{*}{ EBF at 6 months (recall 24 h) } & 1 & 822 & 9.0 & (6.2 to 11.9$)$ & 726 & 7.1 & (3.9 to 10.2$)$ \\
\hline & 2 & 835 & 7.7 & (5.4 to 9.9$)$ & 636 & 8.4 & (4.7 to 12.2$)$ \\
\hline & 3 & 842 & 7.6 & (4.9 to 10.3 ) & 599 & 9.6 & (7.2 to 12.1$)$ \\
\hline \multirow[t]{3}{*}{ EBF at 6 months (recall 7 days) } & 1 & 822 & 5.5 & (3.8 to 7.2 ) & 726 & 5.3 & (2.8 to 7.7 ) \\
\hline & 2 & 835 & 5.6 & (3.7 to 7.4$)$ & 636 & 6.7 & (3.7 to 9.8$)$ \\
\hline & 3 & 842 & 5.4 & (2.7 to 8.0$)$ & 599 & 7.6 & (5.6 to 9.6$)$ \\
\hline \multirow[t]{3}{*}{$\mathrm{ABF}$ at 6 months (recall $24 \mathrm{~h}$ ) } & 1 & 822 & 67.6 & (62.5 to 72.7$)$ & 726 & 62.4 & (55.8 to 69.0 ) \\
\hline & 2 & 835 & 66.7 & (63.5 to 69.9$)$ & 636 & 63.4 & (59.4 to 67.3 ) \\
\hline & 3 & 842 & 69.0 & (66.2 to 71.8$)$ & 599 & 65.4 & (61.4 to 69.5$)$ \\
\hline \multirow[t]{3}{*}{ ABF at 12 months (recall $24 \mathrm{~h}$ ) } & 1 & 777 & 32.4 & (26.6 to 38.2$)$ & 683 & 28.6 & (24.1 to 33.2 ) \\
\hline & 2 & 820 & 34.9 & (32.4 to 37.5$)$ & 611 & 30.8 & (24.0 to 37.6$)$ \\
\hline & 3 & 817 & 36.2 & (32.4 to 40.1$)$ & 592 & 34.9 & (30.9 to 39.0 ) \\
\hline
\end{tabular}


Table 3 Adjusted rates (per cent) of exclusive (EBF) and any ( $A B F)$ breast feeding at different ages and with different recall periods by compliance with the intervention and round of data collection

\begin{tabular}{|c|c|c|c|c|c|c|c|}
\hline \multirow[b]{2}{*}{ Breastfeeding indicators } & \multirow[b]{2}{*}{ Round } & \multicolumn{3}{|c|}{ Compliance group } & \multicolumn{3}{|c|}{ Non-compliance group } \\
\hline & & $\mathrm{n}$ & Per cent & $(95 \% \mathrm{Cl})$ & $\mathrm{n}$ & Per cent & $(95 \% \mathrm{Cl})$ \\
\hline \multirow[t]{3}{*}{ EBF at 3 months (recall $24 \mathrm{~h}$ ) } & 1 & 978 & 60.6 & $(56.2 \text { to } 65.0)^{\star}$ & 620 & 47.6 & $(43.6 \text { to } 51.6)^{*} \dagger$ \\
\hline & 2 & 979 & 58.4 & (54.9 to 61.9 ) & 511 & 51.0 & (42.8 to 59.1 ) \\
\hline & 3 & 993 & 63.5 & $(61.4 \text { to } 65.7)^{*}$ & 507 & 54.5 & $(51.7 \text { to } 57.3)^{*} \dagger$ \\
\hline \multirow[t]{3}{*}{ EBF at 3 months (recall 7 days) } & 1 & 978 & 51.1 & $(46.1 \text { to } 56.1)^{*}$ & 620 & 39.7 & $(35.6 \text { to } 43.8)^{\star} \dagger$ \\
\hline & 2 & 979 & 53.9 & (49.6 to 58.3 ) & 511 & 47.3 & (38.7 to 55.9 ) \\
\hline & 3 & 993 & 56.8 & $(53.7 \text { to } 59.9)^{*}$ & 507 & 48.1 & $(45.1 \text { to } 51.2)^{*} \dagger$ \\
\hline \multirow[t]{3}{*}{ EBF at 6 months (recall $24 \mathrm{~h}$ ) } & 1 & 947 & 9.8 & (7.0 to 12.6$)$ & 601 & 5.6 & (2.5 to 8.7 ) \\
\hline & 2 & 956 & 8.3 & (5.5 to 11.1 ) & 515 & 7.5 & (4.1 to 10.9 ) \\
\hline & 3 & 951 & 9.4 & (6.8 to 12.1$)$ & 490 & 6.5 & (3.5 to 9.5$)$ \\
\hline \multirow[t]{3}{*}{ EBF at 6 months (recall 7 days) } & 1 & 947 & 6.3 & (4.6 to 7.9 ) & 601 & 4.2 & (1.7 to 6.8$)$ \\
\hline & 2 & 956 & 6.4 & (4.0 to 8.8$)$ & 515 & 5.6 & (3.1 to 8.1 ) \\
\hline & 3 & 951 & 7.0 & (4.1 to 9.9 ) & 490 & 4.7 & (2.6 to 6.8 ) \\
\hline \multirow[t]{3}{*}{ ABF at 6 months (recall $24 \mathrm{~h}$ ) } & 1 & 947 & 68.9 & (64.4 to 73.3 ) & 601 & 59.1 & (53.2 to 65.0 ) \\
\hline & 2 & 956 & 67.4 & $(65.2 \text { to } 69.6)^{*}$ & 515 & 61.1 & $(57.3 \text { to } 65.0)^{*}$ \\
\hline & 3 & 951 & 70.3 & $(67.6 \text { to } 73.1)^{\star}$ & 490 & 62.1 & $(59.6 \text { to } 64.6)^{*}$ \\
\hline \multirow[t]{3}{*}{ ABF at 12 months (recall $24 \mathrm{~h}$ ) } & 1 & 890 & 33.5 & (28.5 to 38.5 ) & 570 & 26.2 & (21.7 to 30.7 ) \\
\hline & 2 & 931 & 35.3 & (32.2 to 38.4 ) & 500 & 29.3 & (22.3 to 36.3 ) \\
\hline & 3 & 930 & 37.6 & (34.3 to 40.9 ) & 479 & 32.1 & (28.0 to 36.1 ) \\
\hline
\end{tabular}

${ }^{*} \mathrm{p}<0.05$ between groups.

$t p<0.05$ between rounds.

rates of breast feeding may be longer than the duration of the project. So far, six LHAs, all in the early intervention group, were accredited as Baby Friendly after passing three phases of external evaluation: two in 2012, close to the end of the research project, three in 2014 and one in 2015, 2 and 3 years after the end of the research project; other LHAs are still working towards accreditation. Third, the 18 LHAs that volunteered to participate in the study were already highly committed to the promotion of breast feeding, compared with other LHAs nationwide, as shown by the presence of accredited BFHs in one-third of the study areas. The implementation of the seven steps might have occurred at a time when breast feeding was already on the rise. Lastly, the baseline rates of breast feeding at 3,6 and 12 months of our 18 LHAs were higher than those commonly reported in Italy, ${ }^{83}$ partly due to the aforementioned commitment to the promotion of breast feeding and partly because they are located in northern and central Italy, where rates of breast feeding are usually higher than in southern regions. ${ }^{34}$ It may be harder to increase breastfeeding rates starting from a higher than from a lower level.

A comparison with the trends in the rates of breast feeding in the same regions where the 18 participating LHAs are located, and during approximately the same period, may help one understand if the small increases reported were associated with BFCI activities or not. This is possible only for three regions: Lombardia ( 5 out of its 15 LHAs were included in the BFCI project), Emilia Romagna (3 of 11) and Friuli Venezia Giulia (2 of 6). In Lombardia, the rate of EBF at the first immunisation (2-3 months of age) was $38 \%$ in 2006 and $47 \%$ in 2012; at the second (around 5 months of age), it went up from $19 \%$ to $27 \%$ in the same period. ${ }^{35}$ In Emilia Romagna, the rates of $\mathrm{EBF}$ at the first and second immunisation went up from $47 \%$ to $48 \%$ and down from $41 \%$ to $30 \%$, respectively, between 2008 and $2011 .{ }^{36}$ In Friuli Venezia Giulia, the rate of EBF at the second immunisation was $38 \%$ in $2004,{ }^{37}$ and it went down to $34 \%$ in $2011 .{ }^{38}$ Our data, however, are very accurate; the age of the infant, for example, is the exact age plus or minus a week. Instead, the data from the three regions above refer to infants whose ages may be within a range of 1-2 months. They may also be less standardised, and perhaps biased, because they are gathered by professionals in their own LHA, while our data were collected by independent interviewers. The samples used in routine surveillance systems may also be less representative than in our sample. Recently, the National Institute of Statistics published a preliminary report of a survey on pregnancy, childbirth and breast feeding carried out in 2013 on a nationally representative sample. ${ }^{39}$ The results, which are not yet broken down by region, show that between 2005 and 2013 the initiation of breast feeding went up from $81.4 \%$ to $85.5 \%$, while the median duration increased from 7.3 to 8.3 months, with small differences between macroregions. The survey indicates that there is a general upward trend, but unfortunately it does not allow one to gauge the effect of the BFCI, because it does not report trends in the rates of EBF.

Our study has some limitations. Since it was impossible to randomise the 18 LHAs, the results may be biased by some residual confounding, despite our efforts to adjust data for well-known confounders before any comparison 
between groups. As already mentioned, our study might not have the power to identify small statistically significant improvements in breastfeeding rates. In addition, it may have been too short: the effects of the BFCI may become evident over a longer period. Finally, our study was carried out in a real-life situation. This means that the actual implementation of the intervention did not necessarily follow the timing and mode proposed by the research protocol, and was instead adapted to each reality and tailored to the local situation. ${ }^{21}$ For example, the development and approval of a written policy (step 1) may take different amounts of time in different LHAs, because of factors such as the continuity and commitment of decision makers, as well as the complexity of the organisation. Some of the 18 LHAs are small and compact, whereas others are large and located in cities like Rome, Milan and Bologna, where the number of actors is much higher. This has a bearing on the implementation of step 2; it is easier to conduct courses where the number of health professionals is small and stable, while it is much more difficult to achieve a high coverage with large numbers of professionals and a high turnover. Similar considerations are relevant for the other steps, and particularly for step 6 , the provision of a welcoming atmosphere for breastfeeding families, and step 7, the promotion of cooperation between healthcare staff, breastfeeding support groups and the local community, which are closely related. With such a heterogeneous and continuously changing group of study units, it was difficult to decide what to compare with what, making the interpretation of results very problematic.

To conclude, the BFCI is a complex intervention carried out in socially and geographically different areas. ${ }^{22}$ Implementing the seven steps requires years of hard work geared towards sustainable changes by policymakers and decision makers, all categories of health professionals, public and private health organisations, mother-to-mother support groups, volunteer organisations and local administrators. The challenge is to modify the practices of healthcare professionals and achieve organisational changes, an objective that is hard to achieve even in the BFHI, ${ }^{32}{ }^{40}$ a much less complex initiative, as well as to shape and activate mutually supportive networks. It was encouraging to see all the coordinated efforts being made in a coordinated way in the 18 LHAs that volunteered to participate in this project. However, complex interventions are difficult to implement; it is also difficult to assess their effects in real life. ${ }^{41}$ The design and methods used in this study are far from perfect, but it would be difficult to measure the effect of the BFCI, if any, using the rigorous methods of a randomised controlled trial. The project is already bringing about changes in the way breast feeding is protected, promoted and supported in the 18 LHAs. This study does not allow one to determine whether the BFCI is effective or ineffective, but it has paved the way for better practices in the 18 LHAs and hopefully in other regions of Italy and in other countries.
Author affiliations

${ }^{1}$ Health Services Research and International Health, Institute for Maternal and Child Health IRCCS Burlo Garofolo, Trieste, Italy

${ }^{2}$ Maternal and Child Health Unit, Department of Primary Care, Local Health Authority, Milan, Italy

${ }^{3}$ Baby Friendly Initiatives, Italian Committee for UNICEF, Rome, Italy

${ }^{4}$ National Council for Technological and Scientific Development, Porto Alegre, Brazil

${ }^{5}$ Management and Health Laboratory, Institute of Management, Scuola Superiore Sant'Anna, Pisa, Italy

${ }^{6}$ Department of Epidemiology and Biostatistics, Institute for Maternal and Child Health IRCCS Burlo Garofolo, Trieste, Italy

Acknowledgements The authors thank Leonardo Speri, former coordinator of the BFHI/BFCl Task Force of the Italian Committee for UNICEF, who strongly supported the idea of setting up this research project.

Collaborators The following are members of the BFCl Study Group, in addition to the main authors: Alessandra Knowles, Paola Pani, Claudia Carletti (Institute for Maternal and Child Health IRCCS Burlo Garofolo, Trieste); Annacatia Miola, Stefania Battocchio, Paola Dal Zotto (Local Health Authority, Bassano del Grappa); Emiliana Mosca, Angelo Penna, Antonella Tedesco (Local Health Authority, Biella); Franco Garofalo, Anna Perona (Department of Paediatrics, Biella Hospital); Paola Lenzi, Marilina Colombo, Cledemaria Garavini (Local Health Authority, Bologna); Massimo Farneti, Marcella Lombardi (Local Health Authority, Cesena); Anna Maria Baldoni, Laura Borghesi, Paola Dalla Casa, Enrico Marchiani, Claudia Zoli (Local Health Authority, Forlì); Federica Braida, Oriana Raminelli, Anna Furlan (Local Health Authority, Pordenone); Fiorella Talassi, Loretta Grossi, Gabriele Gianella, Paola Mussini (Local Health Authority, Mantova); Rita Gatti, Grazia Pompilio (Maternal and Child Health Centre, Loreto); Marco Morbidoni (Department of Epidemiology, Ancona); Mauro Tiriduzzi, Nadia Liberatore, Susi Campanari, Paola Catena (Department of Obstetrics and Gynaecology, Osimo Hospital); Laura Polenta, Roberta Freddara (Salesi Hospital, Ancona); Fabiola Salvetti, Cinzia Luzi, Romana Prosperi Porta (Department of Pediatrics, Massa Carrara Hospital); Rita Mascheroni, Miriam Lelli, Graziella Cattaneo, Raffaella Gennaretti, Antonia Tomaselli (Local Health Authority, Milan); Maria Elena Pirola, Domenico Arensi, Giovanni Beghi, Gigliola Ronchi, Piera Ceresa, Silvano Santucci (Local Health Authority, Milan 1); Luigi Acerbi, Maura Franzetti, Roberto Lucchini, Giuseppina De Gasperi (Local Health Authority, Milan 2); Maria Antonietta Grimaldi (Local Health Authority, Oristano); Patrizia Auriemma, Patrizia Proietti, Elisa Lazzaro (Local Health Authority, Rome B); Eloisa Del Curto, Patrizia Sossi, Livia Tabacchi, Paola Abbiati (Local Health Authority, Sondrio); Maria Vittoria Sola (Local Health Authority, Trieste); Andrea Guala, Raffaella Visentin, Luigina Boscardini, Elena Ferzetti, Laura Cantalupi (Local Health Authority, Verbano-Cusio-Ossola); Emanuela Battisti, Daniela Dainese, Francesca Lazzari, Elisa Pastorelli (Local Health Authority, Verona).

Contributors AC designed and coordinated the study, participated in data analysis and interpretation, and drafted and revised the paper. He acts as guarantor. MEB and EC pilot tested and developed the BFCI tools used in the study, were in charge of monitoring the implementation of $\mathrm{BFCl}$ activities by gathering and analysing periodic reports from the study sites, and contributed to the interpretation of results. AM and LCdES centralised and checked all the data gathered in the three rounds of data collection in a continuous feedback with the study sites, were in charge of making the data sets ready for analysis, and contributed to the interpretation of results. AMM was responsible for all the CATI interviews and prepared the relative data sets. MM carried out the statistical analysis. All the members of the BFCI Study Group participated in the implementation of $\mathrm{BFCl}$ activities and in the collection of data for the first interview. All coauthors, including the members of the BFCl Study Group, approved the final version of the manuscript.

Funding This work was supported by a financial contribution from the Institute for Maternal and Child Health IRCCS Burlo Garofolo, Trieste, Italy (research grant n. 32/08), and by funds made available by the Italian Committee for UNICEF and by each of the participating LHAs for local activities. The study could not have been carried out without the commitment of dozens of dedicated health professionals in the 18 study sites, too many to name individually, and the dedication of the interviewers based at the School of Management and Health in Pisa, Italy. 
Competing interests None declared.

\section{Patient consent Obtained.}

Ethics approval The study was approved by the Ethics Committees of the Institute for Maternal and Child Health IRCCS Burlo Garofolo in Trieste and of the 18 participating Local Health Authorities: Bassano del Grappa, Biella, Bologna, Cesena, Forlì, Friuli Occidentale, Mantova, Marche, Massa Carrara, Milano, Milano 1, Milano 2, Oristano, Roma B, Sondrio, Trieste, Verbania and Verona.

Provenance and peer review Not commissioned; externally peer reviewed.

Data sharing statement The full data set is available on reasonable request from the corresponding author at adriano.cattaneo@burlo.trieste.it. The presented data are anonymised and risk of identification is low.

Open Access This is an Open Access article distributed in accordance with the Creative Commons Attribution Non Commercial (CC BY-NC 4.0) license, which permits others to distribute, remix, adapt, build upon this work noncommercially, and license their derivative works on different terms, provided the original work is properly cited and the use is non-commercial. See: http:// creativecommons.org/licenses/by-nc/4.0/

\section{REFERENCES}

1. Kramer MS, Chalmers B, Hodnett ED, et al. Promotion of Breastfeeding Intervention Trial (PROBIT): a randomized trial in the Republic of Belarus. JAMA 2001;285:413-20.

2. Cattaneo A, Buzzetti R. Effect on rates of breast feeding of training for the Baby Friendly hospital initiative. BMJ 2001;323:1358-62.

3. WHO. Global strategy for infant and young child feeding. Geneva: WHO, 2002

4. Ministero della Salute. Linee di indirizzo nazionali sulla protezione, la promozione ed il sostegno dell'allattamento al seno. Rome: Gazzetta Ufficiale, 2008

5. International Lactation Consultant Association. Position paper on infant feeding. Raleigh, NC: ILCA, 2000.

6. American Academy of Pediatrics Section on Breastfeeding. Breastfeeding and the use of human milk. Pediatrics 2012;129: e827-41.

7. National Center for Chronic Disease Prevention and Health Promotion. Breastfeeding among U.S. children born 1999-2006, CDC National Immunization Survey. Atlanta, GA: CDC, 2010.

8. Cattaneo A, Burmaz T, Arendt M, et al. Protection, promotion and support of breast-feeding in Europe: progress from 2002 to 2007. Public Health Nutr 2010;13:751-9.

9. Cai X, Wardlaw T, Brown DW. Global trends in exclusive breastfeeding. Int Breastfeed J 2012;7:12.

10. Casanovas C, Saadeh R. Scaling up protection, promotion, and support of breastfeeding at the community level. Food Nutr Bull 2009;30:S230-5.

11. Guise JM, Palda V, Westhoff C, et al. The effectiveness of primary care-based interventions to promote breastfeeding: systematic evidence review and meta-analysis for the US Preventive Services Task Force. Ann Fam Med 2003;1:70-8.

12. Ingram J, Johnson D, Condon L. The effects of Baby Friendly Initiative training on breastfeeding rates and the breastfeeding attitudes, knowledge and self-efficacy of community health-care staff. Prim Health Care Res Dev 2011;12:266-75.

13. Renfrew MJ, Dyson L, Wallace L, et al. The effectiveness of public health interventions to promote the duration of breastfeeding. London: National Institute for Health and Clinical Excellence, 2005.

14. Coutinho SB, de Lira PI, de Carvalho LM, et al. Comparison of the effect of two systems for the promotion of exclusive breastfeeding. Lancet 2005;366:1094-100.

15. Morrow AL, Guerrero ML, Shults J, et al. Efficacy of home-based peer counselling to promote exclusive breastfeeding: a randomised controlled trial. Lancet 1999;353:1226-31.
16. Pisacane A, Continisio GI, Aldinucci M, et al. A controlled trial of the father's role in breastfeeding promotion. Pediatrics 2005;116: e494-8.

17. Tohotoa J, Maycock B, Hauck YL, et al. Dads make a difference: an exploratory study of paternal support for breastfeeding in Perth, Western Australia. Int Breastfeed J 2009;4:15.

18. Unicef UK. Baby Friendly Initiative implementation guidance. London, UK: UNICEF, 2010.

19. New Zealand Breastfeeding Authority. Baby Friendly Community Initiative: getting started. New Zealand Breastfeeding Authority, Christchurch, 2010.

20. Breastfeeding Committee for Canada. BFI integrated 10 steps practice outcome indicators for hospitals and community health services. Drayton Valley, AB: National Authority for the Baby-Friendly Initiative, 2011.

21. Dyson L, Renfrew MJ, McFadden A, et al. Policy and public health recommendations to promote the initiation and duration of breast-feeding in developed country settings. Public Health Nutr 2010;13:137-44.

22. Bettinelli ME, Chapin EM, Cattaneo A. Establishing the Baby-Friendly Community Initiative in Italy: development, strategy, and implementation. J Hum Lact 2012;28:297-303.

23. Renfrew MJ, Spiby H, D'Souza L, et al. Rethinking research in breast-feeding: a critique of the evidence base identified in a systematic review of interventions to promote and support breast-feeding. Public Health Nutr 2007;10:726-32.

24. Macaluso A, Bettinelli ME, Chapin EM, et al. A controlled study on baby-friendly communities in Italy: methods and baseline data. Breastfeed Med 2013;8:198-204.

25. Aarts C, Kylberg E, Hornell A, et al. How exclusive is exclusive breastfeeding? A comparison of data since birth with current status data. Int J Epidemiol 2000;29:1041-6.

26. Bland RM, Rollins NC, Solarsh G, et al. Maternal recall of exclusive breast feeding duration. Arch Dis Child 2003;88:778-83.

27. World Health Organization. Indicators for assessing infant and young child feeding practices: part 1 definitions. Geneva: WHO, 2009.

28. World Health Organization. Indicators for assessing infant and young child feeding practices: part 2 measurement. Geneva: WHO, 2010.

29. UNICEF, WHO. Baby Friendly Hospital Initiative. Revised, updated and expanded for integrated care. Section 4: hospital self-appraisal and monitoring. New York: UNICEF, 2009.

30. ISTAT. Essere madri in Italia. Rome: ISTAT, 2007.

31. ISTAT. Natalità e fecondità della popolazione residente nel 2011. Rome: ISTAT, 2012.

32. Semenic S, Childerhose JE, Lauziere J, et al. Barriers, facilitators, and recommendations related to implementing the Baby-Friendly Initiative (BFI): an integrative review. J Hum Lact 2012;28:317-34.

33. Giovannini M, Riva E, Banderali G, et al. Feeding practices of infants through the first year of life in Italy. Acta Paediatr 2004;93:492-7.

34. Giovannini M, Banderali G, Agostoni C, et al. Epidemiology of breastfeeding in Italy. Acta Paediatr Suppl 1999;88:19-22.

35. Pirola ME, Bettinelli ME, Bonfanti M, et al. Prevalenza, esclusività e durata dell'allattamento al seno in Regione Lombardia. Milano: Regione Lombardia, 2012.

36. Marchetti F. Prevalenza dell'allattamento al seno e altri interventi preventivi in Emilia Romagna. Med Bambino 2013;32:223-5.

37. Cattaneo A, Giuliani C. Breastfeeding in Friuli Venezia Giulia. Eur J Public Health 2006;16:111.

38. Cuoghi C, Di Mario S, Borgini B, et al. Prevalenza dell'allattamento al seno e altri interventi preventivi in Emilia-Romagna. Bologna: Regione Emilia Romagna, 2011.

39. ISTAT. Gravidanza, parto e allattamento al seno, anno 2013. Rome: ISTAT, 2014.

40. Schmied V, Gribble K, Sheehan A, et al. Ten steps or climbing a mountain: a study of Australian health professionals' perceptions of implementing the baby friendly health initiative to protect, promote and support breastfeeding. BMC Health Serv Res 2011;11:208.

41. Campbell NC, Murray E, Darbyshire J, et al. Designing and evaluating complex interventions to improve health care. BMJ 2007;334:455-9. 